\title{
BMJ Open Occupational exposure to solvents and risk of head and neck cancer in women: a population-based case-control study in France
}

\author{
Matthieu Carton, ${ }^{1,2}$ Christine Barul, ${ }^{3}$ Gwenn Menvielle, ${ }^{4}$ Diane Cyr, ${ }^{1,2}$ \\ Marie Sanchez, ${ }^{5,6}$ Corinne Pilorget, ${ }^{7,8}$ Brigitte Trétarre, ${ }^{9}$ Isabelle Stücker, ${ }^{5,6}$ \\ Danièle Luce, ${ }^{3}$ for the ICARE Study Group
}

To cite: Carton M, Barul C, Menvielle G, et al. Occupational exposure to solvents and risk of head and neck cancer in women: a population-based casecontrol study in France. BMJ Open 2017;7:e012833. doi:10.1136/bmjopen-2016012833

- Prepublication history and additional material is available. To view please visit the journal (http://dx.doi.org/ 10.1136/bmjopen-2016012833).

Received 30 May 2016 Revised 26 September 2016 Accepted 11 November 2016

CrossMark

For numbered affiliations see end of article.

Correspondence to Dr Danièle Luce; daniele.luce@inserm.fr

\section{ABSTRACT}

Objective: Our objective was to investigate the association between head and neck cancer and occupational exposure to chlorinated, oxygenated and petroleum solvents in women.

Methods: Investigation of occupational and environmental CAuses of REspiratory cancers (ICARE), a French population-based case-control study, included 296 squamous cell carcinomas of the head and neck (HNSCC) in women and 775 female controls. Lifelong occupational history was collected. Job-exposure matrices allowed to assess exposure to 5 chlorinated solvents (carbon tetrachloride; chloroform; methylene chloride; perchloroethylene; trichloroethylene), 5 petroleum solvents (benzene; special petroleum product; gasoline; white spirits and other light aromatic mixtures; diesel, fuels and kerosene) and 5 oxygenated solvents (alcohols; ketones and esters; ethylene glycol; diethyl ether; tetrahydrofuran). OR and $95 \% \mathrm{Cls}$, adjusted for smoking, alcohol drinking, age and geographical area, were estimated with logistic models. Results: Elevated ORs were observed among women ever exposed to perchloroethylene $(\mathrm{OR}=2.97,95 \% \mathrm{Cl}$ 1.05 to 8.45$)$ and trichloroethylene $(0 \mathrm{R}=2.15,95 \% \mathrm{Cl}$ 1.21 to 3.81 ). These 0 Rs increased with exposure duration $(\mathrm{OR}=3.75,95 \% \mathrm{Cl} 0.64$ to 21.9 and $\mathrm{OR}=4.44$, $95 \% \mathrm{Cl} 1.56$ to 12.6 for 10 years or more, respectively). No significantly increased risk of HNSCC was found for occupational exposure to the other chlorinated, petroleum or oxygenated solvents.

Conclusions: These findings suggest that exposure to perchloroethylene or trichloroethylene may increase the risk of HNSCC in women. In our study, there is no clear evidence that the other studied solvents are risk factors for HNSCC.

\section{INTRODUCTION}

Compared with other European Union countries, head and neck cancers are frequent in France. ${ }^{1}$ Age-standardised (world population) incidence rates in 2012 in France were 16.1

\section{Strengths and limitations of this study}

- Little is known about occupational risk factors for head and neck cancer in women. Our study is one of the largest studies on this topic.

- The study was population-based; exposure to solvents was assessed from the entire occupational history, obtained from in-person interviews.

- Special attention was paid to adjustment for alcohol and tobacco consumption.

- Exposure assessment through job-exposure matrices may entail misclassification of exposure, which is likely to be non-differential.

- Despite a relatively large number of cases, statistical power was limited for in-depth analyses by cancer sites.

per 100000 for lip, oral cavity and pharynx (LOCP) cancers and 5.4 per 100000 for laryngeal cancer in men, and 5.6 per 100000 for LOCP and 0.9 per 100000 for laryngeal cancer in women. Moreover, in 1980-2012, the incidence of LOCP cancer and laryngeal cancer increased by $60 \%$ and $50 \%$, respectively, in women, while it decreased by $60 \%$ and $62 \%$, respectively, in men. ${ }^{2}$

Tobacco smoking and alcohol consumption are well established major risk factors for these cancers, ${ }^{3}$ and the joint effect of tobacco and alcohol is at least multiplicative. ${ }^{4}$

In addition to these major risk factors, several studies have investigated the role of occupational exposures in the occurrence of head and neck cancers. Thus, some occupations in $\mathrm{men}^{5-17}$ and women ${ }^{14}{ }^{18-21}$ were associated with the risk of developing head and neck cancer.

In a previous analysis by occupation among women, ${ }^{22}$ we found a high risk of head and neck cancer associated with various 
occupations and industries, among them electrical and electronic equipment assemblers, radio, television and communication equipment manufacturing, flame cutters, welders and printers, which suggested a possible role of exposure to solvents. Some studies have shown an increased risk of head and neck cancer associated with exposure to solvents. ${ }^{23}{ }^{24}$ Some solvents such as trichloroethylene (TCE), ${ }^{25}$ perchloroethylene $(\mathrm{PCE})^{25}$ or benzene ${ }^{26}$ are classified as proven or probable carcinogens by International Agency for Research on Cancer (IARC), but for cancer sites other than head and neck.

The majority of results on the association between solvent exposures and cancers of the upper aerodigestive tract were observed in studies conducted in men and very few studies were conducted among women. However, chlorinated and oxygenated solvents are commonly used by women. ${ }^{27}$ In addition, circumstances of exposure can vary between men and women and some studies have suggested gender differences in the toxicokinetics of solvents. ${ }^{28}{ }^{29}$ Investigation of occupational and environmental CAuses of REspiratory cancers (ICARE), one of the largest population-based case-control studies of head and neck cancer, offers the opportunity to study the association between cancer of the head and neck and occupational exposures to chlorinated, oxygenated and petroleum solvents in women.

\section{MATERIALS AND METHODS}

Study population

ICARE has been described in detail previously. ${ }^{30}$ Briefly, ICARE is a multicentre, population-based case-control study, which included a group of 2926 lung cancer cases, a group of 2415 head and neck cancer cases and a common control group of 3555 subjects. Incident cases were identified in collaboration with cancer registries in 10 geographical areas in France. All incident primary cancer cases of the head and neck diagnosed between 2001 and 2007 were included, comprising malignant neoplasms of the LOCP (C00-C14), nasal cavity and accessory sinuses (C30.0, C31) and larynx (C32) as coded by the International Classification of Diseases for Oncology, third edition (ICD-O-3). Included cases were histologically confirmed cases, aged 18 years to 75 years at diagnosis. All histological types were included. The control group was a random sample of the population of the same geographical areas, with a distribution by sex and age comparable to that of head and neck cancer and lung cancer cases, and a distribution by socioeconomic status (SES) comparable to that of the general population. Subjects were interviewed face to face, using a standardised questionnaire collecting information on lifetime tobacco and alcohol consumption, residential history and a detailed description of occupational history. Participation rates were $80.6 \%$ among controls and $82.5 \%$ among cases. ${ }^{30}$

Each subject gave written informed consent.

\section{Study sample}

Only women were considered in this analysis. In all, 361 female head and neck cancer cases were included in the ICARE study. The present analysis was restricted to squamous cell carcinomas of the following cancer sites: (1) oral cavity, 88 cases $(29.7 \%)$ : ICD-O-3 codes C00.3$\mathrm{C} 00.9$, C02.0-C02.3, C03, C04, C05.0 and C06; (2) oropharynx, 111 cases $(37.5 \%)$ : codes C01.9, C02.4, C05.1, C05.2, C09 and C10; (3) hypopharynx, 28 cases $(9.5 \%)$ : codes C12- C13; (4) oral cavity, pharynx unspecified or overlapping, 22 cases (7.4\%): codes C02.8, C02.9, C05.8, C05.9 and C14; (5) larynx, 47 cases (15.9\%): codes C32. There were 296 cases and 775 controls in the final study group.

\section{Coding of job titles}

Each job held for at least 1 month was coded using the International Standard Classification of Occupations $(\text { ISCO })^{31}$ and the Nomenclature des Activités Françaises (NAF), ${ }^{32}$ the French classification for industrial activities. Occupational histories were coded by specially trained coders blind as to the case-control status.

\section{Exposure assessment}

Occupational exposure to five chlorinated solvents (carbon tetrachloride; chloroform; methylene chloride; PCE; TCE), five petroleum solvents (benzene; special petroleum product; gasoline; white spirits and other light aromatic mixtures; diesel, fuels and kerosene) and five oxygenated solvents (alcohols; ketones and esters; ethylene glycol; diethyl ether; tetrahydrofuran) was assessed using job-exposure matrices (JEMs) developed for the French population by the French Institute of Health Surveillance. ${ }^{33}$ For each combination of ISCO and NAF codes, the JEMs assigned three exposure indices: (1) probability of exposure expressed as the percentage of exposed workers, (2) intensity of exposure and (3) frequency of exposure. For these three indices, different categories were used depending on the solvent considered (see online supplementary material table SI).

To account for changes in exposure over time, different indices were provided for different calendar periods from 1947 to 2007. Exposure information for the earliest period was used for jobs held before 1947.

'Ever exposed' to a specific solvent refers to subjects having had at least one job with probability of exposure $>0$. Cumulative duration of exposure was computed by summing all exposed periods.

Cumulative Exposure Indices (CEIs) were obtained by summing the product of exposure probability, frequency, intensity and duration for each job period, over the lifetime occupational history, using the central value of each of the three classes. We also calculated the average exposure intensity, as the CEI divided by the total duration of exposure. 


\section{Statistical analysis}

Exposure duration, average exposure intensity and CEI were used as continuous variables. We first used restricted cubic splines (4 knots) to check the linearity assumption. None of the tests for departure from linearity were significant. Exposure variables were also categorised (cut points: 10 years for duration, median of the distributions among controls for average intensity and CEI). In all analyses, 'never exposed' refers to subjects never exposed to a specific solvent and was used as the reference category.

Owing to the low exposure prevalence for most solvents among women, we favoured sensitivity over specificity by using a broad definition of ever exposure (probability $>0$ ). We also conducted additional analyses using different cut-off points for probability, in order to increase specificity.

Unconditional logistic regression was used to estimate ORs and corresponding 95\% CIs of head and neck cancers. Analyses were adjusted for geographical area (ten 'départements'), age, smoking status (never smoker, former smoker and current smoker), tobacco consumption in pack-years and alcohol consumption in drink-years. Cubic splines were used for alcohol and tobacco because they allowed to better take into account their effects, according to the Bayesian information criterion. Since interactions between smoking status and alcohol consumption, and between smoking status and tobacco consumption, were significant, all models included these interaction terms.

Additional adjustments were made for SES assessed by the last occupation held and by the longest held occupation. Since additional adjustment for SES did not markedly change the results, while it increased the number of parameters to be estimated, the ORs reported in the results section are those not adjusted for SES. Adjustment for asbestos exposure was also performed but did not modify the estimates and these results are not presented here.

ORs were also estimated for each cancer site (as described above: oral cavity, oropharynx, hypopharynx and larynx) using polytomous logistic regression.

Statistical analyses were performed using STATA software (StataCorp LP 2015; V. 13.1). All $\mathrm{p}$ values were twosided and a $p$ value $\leq 0.05$ was used as a threshold for statistical significance.

\section{RESULTS}

The main characteristics of cases and controls are presented in table 1 . On average, cases were 2 years younger than controls. This is explained by the fact that controls were stratified on age (in four categories: $<40$ years, $40-54$ years, $55-64$ years and $>65$ years) based on the age distribution of head and neck cancer cases and lung cancer cases. The SES of cases was lower than that of controls. Cases were less likely to be never smokers or never drinkers than controls. Table 2 shows the numbers and proportions of cases and controls exposed to the various chlorinated, petroleum and oxygenated solvents. The prevalence of exposure was low (10\% or less among controls) for most of the specific solvents, with the exception of white spirits and alcohols, for which $32 \%$ and $48 \%$ of the controls were exposed, respectively.

Ever exposure to TCE and to PCE was associated with significantly elevated ORs. No other significant association was found. Additional analyses using a more specific cut point to define ever exposure (probability $>10 \%$ for methylene chloride, probability $>30 \%$ for TCE, probability $>50 \%$ for the other solvents) produced similar results, although the CIs were wider due to the smaller number of exposed women (data not shown).

The number of women ever exposed to chloroform, carbon tetrachloride, motor gasoline, ethylene glycol and tetrahydrofuran was very low; for this reason, these five solvents were excluded from further analyses. Associations between head and neck cancer risk and other exposure variables are given in table 3 .

\section{Chlorinated solvents}

The risk of head and neck cancer increased with the duration of exposure to TCE (table 3). A similar increase in risk with duration of exposure was found for exposure to PCE. No clear relationship was observed between head and neck cancer and average intensity or cumulative exposure to TCE in the categorical analysis, the highest ORs being observed in the lowest cumulative exposure category. However, when average intensity and CEI were considered as continuous variables, significant trends were observed for both. On the other hand, for $\mathrm{PCE}$, average intensity and cumulative exposure were not associated with head and neck cancer.

The distribution of job periods exposed to TCE by occupation (see online supplementary material figure 1) shows that the most frequently exposed occupations were shoes and leather workers, dry cleaners and launderers, rubber and plastics workers, welders and electronics workers. The most frequent sector of activity exposed to TCE was the leather and footwear industry.

Since leather workers may have also been exposed to benzene in the past, we also estimated mutually adjusted ORs for the association between head and neck cancer and exposure to TCE and benzene. The OR for TCE remained significantly elevated $(\mathrm{OR}=2.05,95 \%$ CI 1.04 to 4.01) whereas no association with benzene exposure was found (OR=1.11, 95\% CI 0.52 to 2.36 ).

The distribution of job periods exposed to PCE by occupation (see online supplementary material figure 2) shows that the most frequently exposed occupations were dry cleaners launderers, degreasers and assemblers in electrical and electronic equipment. The most frequent sector of activity was laundry and dry cleaning.

Exposures to TCE and PCE were strongly correlated, and were also correlated to methylene chloride exposure, which makes the interpretation of mutually adjusted 
Table 1 Main characteristics of cases and controls

\begin{tabular}{|c|c|c|c|c|}
\hline & \multicolumn{2}{|c|}{ Cases } & \multicolumn{2}{|c|}{ Controls } \\
\hline & $\bar{n}$ & Per cent & $\bar{n}$ & Per cent \\
\hline \multicolumn{3}{|l|}{ Département } & & $p=0.003$ \\
\hline Calvados & 23 & 7.8 & 104 & 13.4 \\
\hline Doubs+Territoire de Belfort & 1 & 0.3 & 31 & 4.0 \\
\hline Hérault & 44 & 14.9 & 90 & 11.6 \\
\hline Isère & 37 & 12.5 & 94 & 12.1 \\
\hline Loire Atlantique & 38 & 12.8 & 93 & 12.0 \\
\hline Manche & 37 & 12.5 & 65 & 8.4 \\
\hline Bas-Rhin & 33 & 11.2 & 109 & 14.1 \\
\hline Haut-Rhin & 9 & 3.0 & 29 & 3.7 \\
\hline Somme & 54 & 18.2 & 112 & 14.5 \\
\hline Vendée & 20 & 6.8 & 48 & 6.2 \\
\hline \multicolumn{3}{|l|}{ Age at interview, years } & & $\mathrm{p}<0.0001$ \\
\hline Mean $(95 \% \mathrm{Cl})$ & \multicolumn{2}{|c|}{$58.0(56.9$ to 59.0$)$} & \multicolumn{2}{|c|}{60.4 (59.6 to 61.2$)$} \\
\hline \multicolumn{5}{|l|}{ Class (years) } \\
\hline$<50$ & 51 & 17.2 & 160 & 20.6 \\
\hline $50-59.9$ & 109 & 36.8 & 157 & 20.3 \\
\hline $60-69.9$ & 99 & 33.4 & 246 & 31.8 \\
\hline$\geq 70$ & 37 & 12.6 & 212 & 27.3 \\
\hline \multicolumn{3}{|l|}{ Number of jobs held } & & $p=0.01$ \\
\hline Mean $(95 \% \mathrm{Cl})$ & 3.3( & & \multicolumn{2}{|c|}{3.7 (3.4 to 3.8$)$} \\
\hline Range & 18 & & \multicolumn{2}{|c|}{13} \\
\hline \multicolumn{3}{|c|}{ Socioeconomic status (the longest duration) } & & $p=0.001$ \\
\hline Farmers & 3 & 1.1 & 29 & 3.8 \\
\hline Self-employed workers & 14 & 5.1 & 25 & 3.3 \\
\hline Managers & 19 & 6.9 & 74 & 9.7 \\
\hline Intermediate white-collar workers & 28 & 10.1 & 131 & 17.3 \\
\hline Office and sales employees & 150 & 54.1 & 375 & 49.4 \\
\hline Blue-collar workers & 63 & 22.7 & 125 & 16.5 \\
\hline Missing & 19 & - & 16 & - \\
\hline \multicolumn{3}{|l|}{ Smoking } & & $p<0.0001$ \\
\hline Never ${ }^{\star}$ & 60 & 20.3 & 509 & 66.1 \\
\hline Former smokers $†$ & 46 & 15.5 & 134 & 17.4 \\
\hline Current smokers & 190 & 64.2 & 127 & 16.5 \\
\hline Missing & - & & \multicolumn{2}{|l|}{5} \\
\hline \multicolumn{3}{|l|}{ Pack-years (former and current) } & & $p<0.0001$ \\
\hline$<6.89$ & 23 & 9.9 & 100 & 38.5 \\
\hline $6.9-19.9$ & 34 & 14.6 & 87 & 33.5 \\
\hline $20.0-35.24$ & 78 & 33.5 & 47 & 18.1 \\
\hline$\geq 35.25$ & 98 & 42.1 & 26 & 10.0 \\
\hline Missing & 3 & - & 6 & - \\
\hline \multicolumn{3}{|l|}{ Drinking (drink-years) } & & $p<0.0001$ \\
\hline Never & 44 & 15.4 & 177 & 22.9 \\
\hline$<2.79$ & 39 & 13.6 & 173 & 22.4 \\
\hline $2.8-16.3$ & 35 & 12.2 & 172 & 22.3 \\
\hline $16.4-64.9$ & 51 & 17.8 & 155 & 20.0 \\
\hline$\geq 65.0$ & 117 & 40.9 & 96 & 12.4 \\
\hline Missing & 10 & - & 2 & - \\
\hline
\end{tabular}

${ }^{*}$ Non-smokers were subjects who had smoked fewer than 100 cigarettes or equivalent in their lifetime.

†Former smokers were subjects who had stopped smoking at least 2 years before diagnosis (cases)/interview (controls).

ORs difficult. Instead, we studied exposure to exclusive combinations of chlorinated solvents (table 4). No case was exposed only to PCE. The OR associated with TCE alone was high $(\mathrm{OR}=1.81,95 \%$ CI 0.81 to 4.04$)$, but lower than in the analysis reported in table $2(\mathrm{OR}=2.15$, $95 \%$ CI 1.21 to 3.81 ). Exposure to methylene chloride alone was associated with an OR lower than $1(\mathrm{OR}=0.50$,
95\% CI 0.11 to 2.18). A high OR was associated with joint exposure to TCE and PCE (OR=4.47, 95\% CI 1.27 to 15.8 ).

Analyses by cancer sites are presented in table 5 . The OR associated with TCE exposure was elevated for larynx (OR=3.80, 95\% CI 1.55 to 9.32) and oral cavity $(\mathrm{OR}=2.12,95 \% \mathrm{CI} 0.97$ to 4.60$)$, the latter showing a 
Table 2 Association between head and neck cancer and ever exposure to solvents

\begin{tabular}{|c|c|c|c|c|c|c|c|c|c|c|}
\hline & \multicolumn{4}{|c|}{ Never exposed } & \multicolumn{4}{|c|}{ Ever exposed } & \multirow[b]{3}{*}{ OR $^{*}$} & \\
\hline & \multicolumn{2}{|c|}{ Cases } & \multicolumn{2}{|c|}{ Controls } & \multicolumn{2}{|c|}{ Cases } & \multicolumn{2}{|c|}{ Controls } & & \\
\hline & $\mathbf{n}$ & Per cent & $\bar{n}$ & Per cent & $\bar{n}$ & Per cent & $\mathbf{n}$ & Per cent & & \\
\hline Chloroform & 272 & 98.2 & 748 & 98.7 & 5 & 1.8 & 10 & 1.3 & 0.36 & 0.09 to 1.49 \\
\hline Carbon tetrachloride & 271 & 97.9 & 746 & 98.4 & 6 & 2.1 & 12 & 1.6 & 0.36 & 0.09 to 1.55 \\
\hline Methylene chloride & 264 & 95.1 & 728 & 96.1 & 14 & 4.9 & 30 & 3.9 & 1.09 & 0.46 to 2.57 \\
\hline Trichloroethylene & 240 & 86.6 & 697 & 92.2 & 38 & 13.4 & 60 & 7.8 & 2.15 & 1.21 to 3.81 \\
\hline Perchloroethylene & 268 & 96.5 & 744 & 98.3 & 10 & 3.5 & 13 & 1.7 & 2.97 & 1.05 to 8.45 \\
\hline Motors gasoline & 273 & 98.6 & 748 & 98.8 & 4 & 1.4 & 9 & 1.2 & 1.54 & 0.36 to 6.63 \\
\hline Special petroleum product & 251 & 90.5 & 705 & 93 & 27 & 9.5 & 54 & 7.0 & 1.40 & 0.74 to 2.65 \\
\hline Diesel & 264 & 95.1 & 731 & 96.6 & 14 & 4.9 & 26 & 3.4 & 1.79 & 0.75 to 4.29 \\
\hline Benzene & 250 & 90.1 & 709 & 93.5 & 28 & 9.9 & 50 & 6.5 & 1.65 & 0.87 to 3.13 \\
\hline White-spirits & 188 & 68.3 & 513 & 67.8 & 87 & 31.7 & 247 & 32.2 & 1.08 & 0.73 to 1.60 \\
\hline Ethylene glycol & 276 & 99.6 & 752 & 99.3 & 1 & 0.4 & 5 & 0.7 & 1.75 & 0.17 to 18.4 \\
\hline Tetrahydrofuran & 273 & 98.6 & 754 & 99.6 & 4 & 1.4 & 3 & 0.4 & 4.97 & 0.86 to 28.8 \\
\hline Diethyl ether & 252 & 91.2 & 669 & 88.5 & 25 & 8.8 & 88 & 11.5 & 0.65 & 0.36 to 1.19 \\
\hline Ketones & 234 & 84.5 & 675 & 89.2 & 44 & 15.5 & 83 & 10.8 & 1.61 & 0.96 to 2.70 \\
\hline Alcohols & 152 & 55.6 & 394 & 52.4 & 123 & 44.4 & 364 & 47.6 & 0.83 & 0.57 to 1.20 \\
\hline
\end{tabular}

${ }^{*}$ OR adjusted for age at interview, geographical area, alcohol and tobacco consumption.

dose-response relation with duration and cumulative exposure (see online supplementary material table SII; $\mathrm{OR}=6.84,95 \%$ CI 2.11 to 22.1 for duration $>10$ years; $\mathrm{OR}=2.73,95 \%$ CI 1.02 to 7.30 for CEI $>$ median). There was also a suggestion of an increase in laryngeal cancer risk by duration of exposure. PCE exposure was associated with an increased risk of laryngeal $(\mathrm{OR}=7.95,95 \%$ CI 1.92 to 32.9$)$ and oropharyngeal cancers (OR=3.43, $95 \%$ CI 1.01 to 11.8$)$. The small numbers of exposed cases made it difficult to study dose-response relationships.

\section{Petroleum solvents}

The study of the association between head and neck cancer and exposure to petroleum solvents (table 2) showed slight, non-significant elevations in risk for benzene $(\mathrm{OR}=1.65,95 \%$ CI 0.87 to 3.13), diesel $(\mathrm{OR}=1.79,95 \%$ CI 0.75 to 4.29$)$ and special petroleum products $(\mathrm{OR}=1.40,95 \%$ CI 0.74 to 2.65$)$. No doseresponse relationship was found with the duration of exposure, with the average intensity or with CEI (table 3). Exposure to white spirit (table 5) was associated with a non-significantly increased risk of oral cavity cancer $(\mathrm{OR}=1.54,95 \%$ CI 0.90 to 2.66), which increased with CEI $(\mathrm{OR}=1.20,95 \%$ CI 0.56 to 2.54 for $\mathrm{CEI}<$ median; $\mathrm{OR}=1.75,95 \%$ CI 0.91 to 3.37 for $\mathrm{CEI}>$ median) and duration of exposure $(\mathrm{OR}=0.97,95 \%$ CI 0.48 to 1.96 for $<10$ years; OR=2.51, 95\% CI 1.25 to 5.02 for 10 years or more) (see online supplementary material table SIII).

\section{Oxygenated solvents}

With regard to oxygenated solvents (table 2), no elevated risks were associated with diethyl ether $(\mathrm{OR}=0.65$, $95 \%$ CI 0.36 to 1.19$)$ or alcohols $(\mathrm{OR}=0.83,95 \%$ CI 0.57 to 1.20) exposure. An elevated but not significant OR $(\mathrm{OR}=1.61,95 \%$ CI 0.96 to 2.70$)$ was associated with ketones exposure but without dose-response relationship with duration of exposure, average intensity or CEI (table 3). The OR associated with ever exposure to ketones was significantly elevated for laryngeal cancer $(\mathrm{OR}=2.66,95 \%$ CI 1.17 to 6.07$)$ but there was no increase in risk with duration of exposure or CEI (see online supplementary material table SIV).

\section{DISCUSSION}

We studied occupational exposures to chlorinated, petroleum and oxygenated solvents in relation to head and neck cancer risk in women in France. Some solvent exposures associated with an increased risk of cancer in women have been identified, notably exposure to TCE and PCE, with high and significant risks. For TCE, a clear and significant duration-response relationship was found and there was also some evidence of an increase in risk with intensity and cumulative exposure. For PCE, however, the increase in risk with duration was not significant and there was no indication of a dose-response relation with intensity or cumulative exposure. Risks associated with other solvents were sometimes slightly elevated but not significantly so, or without a durationresponse relationship.

TCE is one of the most commonly used chlorinated solvents. It has been used as a metal degreasing product and was also widely used for manually degreasing textiles, or cleaning machinery and equipment when applying paints, glues, adhesives, plastics, rubbers and so on. TCE was recently classified as carcinogenic to humans (Group 1) based on sufficient epidemiological evidence for cancer of the kidney. Most of the information on the association between TCE and cancer risk derives from cohort studies which include only a small number of head and neck cancers, especially among women, and 
Table 3 Association between head and neck cancer and exposure to selected solvents

\begin{tabular}{|c|c|c|c|c|c|c|c|c|c|c|c|c|c|c|c|c|c|c|c|c|c|c|c|c|c|c|c|c|c|c|c|c|}
\hline & \multirow{2}{*}{\multicolumn{2}{|c|}{$\begin{array}{l}\text { Never } \\
\text { exposed }\end{array}$}} & \multicolumn{10}{|c|}{ Duration of exposure } & \multicolumn{10}{|c|}{ Mean intensity level } & \multicolumn{10}{|c|}{ Cumulative Exposure Index } \\
\hline & & & \multicolumn{4}{|c|}{$<10$ years } & \multicolumn{4}{|c|}{$\geq 10$ years } & \multicolumn{2}{|c|}{ Continuous } & \multicolumn{4}{|c|}{$<$ Median } & \multicolumn{4}{|c|}{$\geq$ Median } & \multicolumn{2}{|c|}{ Continuous } & \multicolumn{4}{|c|}{$<$ Median } & \multicolumn{4}{|c|}{$\geq$ Median } & \multicolumn{2}{|c|}{ Continuous } \\
\hline & $\mathrm{OR}^{*}$ & $\mathrm{Cl}$ & $\mathrm{Ca}$ & Co & $\mathrm{OR}^{*}$ & $95 \% \mathrm{Cl}$ & $\mathrm{Ca}$ & Co & $\mathrm{OR}^{\star}$ & $95 \% \mathrm{Cl}$ & $\mathrm{OR}^{*}$ & $95 \% \mathrm{Cl}$ & $\mathrm{Ca}$ & Co & $\mathrm{OR}^{*}$ & $95 \% \mathrm{Cl}$ & $\mathrm{Ca}$ & Co & $\mathrm{OR}^{*}$ & $95 \% \mathrm{Cl}$ & $\mathrm{OR}^{*}$ & $95 \% \mathrm{Cl}$ & $\mathrm{Ca}$ & Co & $\mathrm{OR}^{\star}$ & $95 \% \mathrm{Cl}$ & $\mathrm{Ca}$ & Co & $\mathrm{OR}^{*}$ & $95 \% \mathrm{Cl}$ & $\mathrm{OR}^{\star}$ & $95 \% \mathrm{Cl}$ \\
\hline \multicolumn{33}{|l|}{ Chlorinated solvents } \\
\hline $\begin{array}{l}\text { Methylene } \\
\text { chloride }\end{array}$ & 1 & Ref. & 7 & 21 & 0.85 & $\begin{array}{l}0.28 \text { to } \\
2.56\end{array}$ & 7 & 9 & 1.65 & $\begin{array}{l}0.42 \text { to } \\
6.53\end{array}$ & 0.99 & $\begin{array}{l}0.93 \text { to } \\
1.05\end{array}$ & 4 & 19 & 0.62 & $\begin{array}{l}0.18 \text { to } \\
2.16\end{array}$ & 10 & 11 & 2.02 & $\begin{array}{l}0.60 \text { to } \\
6.84\end{array}$ & 1.23 & $\begin{array}{l}0.77 \text { to } \\
1.97\end{array}$ & 7 & 15 & 1.34 & $\begin{array}{l}0.42 \text { to } \\
4.28\end{array}$ & 7 & 15 & 0.87 & $\begin{array}{l}0.25 \text { to } \\
2.99\end{array}$ & 1.01 & $\begin{array}{l}0.97 \text { to } \\
1.06\end{array}$ \\
\hline Trichloroethylene & 1 & Ref. & 25 & 47 & 1.67 & $\begin{array}{l}0.86 \text { to } \\
3.24\end{array}$ & 13 & 13 & 4.44 & $\begin{array}{l}1.56 \text { to } \\
12.6\end{array}$ & 1.06 & $\begin{array}{l}1.01 \text { to } \\
1.12\end{array}$ & 24 & 30 & 2.62 & $\begin{array}{l}1.24 \text { to } \\
5.54\end{array}$ & 14 & 30 & 1.67 & $\begin{array}{l}0.71 \text { to } \\
3.90\end{array}$ & 1.30 & $\begin{array}{l}1.01 \text { to } \\
1.66\end{array}$ & 20 & 30 & 2.16 & $\begin{array}{l}1.02 \text { to } \\
4.58\end{array}$ & 18 & 30 & 2.13 & $\begin{array}{l}0.94 \text { to } \\
4.84\end{array}$ & 1.02 & $\begin{array}{l}1.01 \text { to } \\
1.04\end{array}$ \\
\hline Perchloroethylene & 1 & Ref. & 8 & 9 & 2.66 & $\begin{array}{l}0.75 \text { to } \\
9.40\end{array}$ & 2 & 4 & 3.75 & $\begin{array}{l}0.64 \text { to } \\
21.9\end{array}$ & 1.06 & $\begin{array}{l}0.97 \text { to } \\
1.17\end{array}$ & 4 & 7 & 3.56 & $\begin{array}{l}0.90 \text { to } \\
14.1\end{array}$ & 6 & 6 & 2.38 & $\begin{array}{l}0.51 \text { to } \\
11.2\end{array}$ & 1.08 & $\begin{array}{l}0.95 \text { to } \\
1.23\end{array}$ & 8 & 7 & 4.09 & $\begin{array}{l}1.15 \text { to } \\
14.6\end{array}$ & 2 & 6 & 1.44 & $\begin{array}{l}0.18 \text { to } \\
11.6\end{array}$ & 1.00 & $\begin{array}{l}0.99 \text { to } \\
1.02\end{array}$ \\
\hline \multicolumn{33}{|l|}{ Petroleum solvents } \\
\hline $\begin{array}{l}\text { Special petroleum } \\
\text { product }\end{array}$ & 1 & Ref. & 19 & 30 & 1.47 & $\begin{array}{l}0.67 \text { to } \\
3.20\end{array}$ & 8 & 24 & 1.30 & $\begin{array}{l}0.47 \text { to } \\
3.65\end{array}$ & 0.99 & $\begin{array}{l}0.94 \text { to } \\
1.04\end{array}$ & 18 & 27 & 1.30 & $\begin{array}{l}0.56 \text { to } \\
3.01\end{array}$ & 9 & 27 & 1.54 & $\begin{array}{l}0.61 \text { to } \\
3.89\end{array}$ & 1.01 & $\begin{array}{l}0.93 \text { to } \\
1.11\end{array}$ & 21 & 27 & 1.51 & $\begin{array}{l}0.68 \text { to } \\
3.35\end{array}$ & 6 & 27 & 1.25 & $\begin{array}{l}0.45 \text { to } \\
3.45\end{array}$ & 1.00 & $\begin{array}{l}0.99 \text { to } \\
1.01\end{array}$ \\
\hline Diesel & 1 & Ref. & 12 & 16 & 2.89 & $\begin{array}{l}1.03 \text { to } \\
8.08\end{array}$ & 2 & 10 & 0.56 & $\begin{array}{l}0.09 \text { to } \\
3.31\end{array}$ & 1.02 & $\begin{array}{l}0.95 \text { to } \\
1.10\end{array}$ & 8 & 14 & 1.56 & $\begin{array}{l}0.49 \text { to } \\
4.97\end{array}$ & 6 & 12 & 2.13 & $\begin{array}{l}0.59 \text { to } \\
7.61\end{array}$ & 1.30 & $\begin{array}{l}0.94 \text { to } \\
1.78\end{array}$ & 6 & 12 & 1.14 & $\begin{array}{l}0.31 \text { to } \\
4.29\end{array}$ & 8 & 14 & 2.52 & $\begin{array}{l}0.82 \text { to } \\
7.74\end{array}$ & 1.00 & $\begin{array}{l}0.97 \text { to } \\
1.03\end{array}$ \\
\hline Benzene & 1 & Ref. & 21 & 35 & 1.77 & $\begin{array}{l}0.85 \text { to } \\
3.67\end{array}$ & 7 & 15 & 1.34 & $\begin{array}{l}0.38 \text { to } \\
4.68\end{array}$ & 1.00 & $\begin{array}{l}0.94 \text { to } \\
1.06\end{array}$ & 20 & 28 & 1.52 & $\begin{array}{l}0.67 \text { to } \\
3.43\end{array}$ & 8 & 22 & 1.87 & $\begin{array}{l}0.71 \text { to } \\
4.96\end{array}$ & 1.38 & $\begin{array}{l}0.36 \text { to } \\
5.22\end{array}$ & 19 & 25 & 1.59 & $\begin{array}{l}0.69 \text { to } \\
3.64\end{array}$ & 9 & 25 & 1.74 & $\begin{array}{l}0.67 \text { to } \\
4.53\end{array}$ & 1.02 & $\begin{array}{l}0.89 \text { to } \\
1.17\end{array}$ \\
\hline White spirits & 1 & Ref. & 50 & 153 & 0.87 & $\begin{array}{l}0.54 \text { to } \\
1.40\end{array}$ & 37 & 94 & 1.45 & $\begin{array}{l}0.83 \text { to } \\
2.52\end{array}$ & 1.01 & $\begin{array}{l}0.99 \text { to } \\
1.04\end{array}$ & 62 & 182 & 1.08 & $\begin{array}{l}0.70 \text { to } \\
1.67\end{array}$ & 25 & 64 & 0.96 & $\begin{array}{l}0.49 \text { to } \\
1.86\end{array}$ & 0.94 & $\begin{array}{l}0.74 \text { to } \\
1.20\end{array}$ & 42 & 118 & 1.04 & $\begin{array}{l}0.62 \text { to } \\
1.74\end{array}$ & 45 & 129 & 1.08 & $\begin{array}{l}0.65 \text { to } \\
1.78\end{array}$ & 1.00 & $\begin{array}{l}0.98 \text { to } \\
1.02\end{array}$ \\
\hline \multicolumn{33}{|c|}{ Oxygenated solvents } \\
\hline Diethyl ether & 1 & Ref. & 9 & 25 & 1.07 & $\begin{array}{l}0.39 \text { to } \\
2.91\end{array}$ & 16 & 63 & 0.52 & $\begin{array}{l}0.25 \text { to } \\
1.07\end{array}$ & 0.98 & $\begin{array}{l}0.95 \text { to } \\
1.01\end{array}$ & 12 & 44 & 0.58 & $\begin{array}{l}0.25 \text { to } \\
1.33\end{array}$ & 13 & 44 & 0.73 & $\begin{array}{l}0.32 \text { to } \\
1.67\end{array}$ & 0.01 & $\begin{array}{l}0.00 \text { to } \\
326\end{array}$ & 13 & 44 & 0.89 & $\begin{array}{l}0.41 \text { to } \\
1.95\end{array}$ & 12 & 44 & 0.46 & $\begin{array}{l}0.19 \text { to } \\
1.10\end{array}$ & 0.70 & $\begin{array}{l}0.41 \text { to } \\
1.27\end{array}$ \\
\hline Ketones & 1 & Ref. & 32 & 55 & 1.71 & $\begin{array}{l}0.94 \text { to } \\
3.11\end{array}$ & 12 & 28 & 1.42 & $\begin{array}{l}0.58 \text { to } \\
3.48\end{array}$ & 1.02 & $\begin{array}{l}0.98 \text { to } \\
1.06\end{array}$ & 22 & 42 & 1.68 & $\begin{array}{l}0.81 \text { to } \\
3.46\end{array}$ & 22 & 41 & 1.56 & $\begin{array}{l}0.79 \text { to } \\
3.06\end{array}$ & 1.11 & $\begin{array}{l}0.92 \text { to } \\
1.35\end{array}$ & 28 & 42 & 2.27 & $\begin{array}{l}1.16 \text { to } \\
4.44\end{array}$ & 16 & 41 & 1.10 & $\begin{array}{l}0.52 \text { to } \\
2.31\end{array}$ & 1.01 & $\begin{array}{l}0.99 \text { to } \\
1.02\end{array}$ \\
\hline Alcohols & 1 & Ref. & 67 & 168 & 0.93 & $\begin{array}{l}0.59 \text { to } \\
1.45\end{array}$ & 56 & 196 & 0.71 & $\begin{array}{l}0.44 \text { to } \\
1.13\end{array}$ & 0.99 & $\begin{array}{l}0.97 \text { to } \\
1.01\end{array}$ & 80 & 255 & 0.76 & $\begin{array}{l}0.50 \text { to } \\
1.15\end{array}$ & 43 & 109 & 0.89 & $\begin{array}{l}0.53 \text { to } \\
1.51\end{array}$ & 1.33 & $\begin{array}{l}0.90 \text { to } \\
1.95\end{array}$ & 57 & 180 & 0.68 & $\begin{array}{l}0.43 \text { to } \\
1.10\end{array}$ & 66 & 184 & 0.95 & $\begin{array}{l}0.61 \text { to } \\
1.48\end{array}$ & 1.01 & $\begin{array}{l}0.98 \text { to } \\
1.03\end{array}$ \\
\hline
\end{tabular}


Table 4 Association between head and neck cancer and exclusive exposure to combinations of chlorinated solvents

\begin{tabular}{|c|c|c|c|c|}
\hline & Cases $(n=284)$ & Controls $(n=767)$ & OR $^{*}$ & $95 \% \mathrm{Cl}$ \\
\hline Never exposed to TRI, PER or MC & 246 & 693 & 1 & \\
\hline TRI only & 20 & 32 & 1.81 & 0.81 to 4.04 \\
\hline PER only & 0 & 3 & - & - \\
\hline TRI and PER & 9 & 7 & 4.47 & 1.27 to 15.8 \\
\hline MC only & 5 & 8 & 0.50 & 0.11 to 2.18 \\
\hline TRI and MC & 8 & 18 & 1.66 & 0.58 to 4.77 \\
\hline TRI and PER and MC & 1 & 3 & 2.16 & 0.19 to 24.1 \\
\hline
\end{tabular}

sometimes do not report results for these cancer sites. Wartenberg $e t a l^{34}$ reviewed data on exposure to TCE and cancer in a meta-analysis. They concluded that there was a weak suggestion of an increased risk of laryngeal cancer, and on average no evidence of an association with oral and pharyngeal cancer, despite substantial heterogeneity between studies. More recently, Raaschou-Nielsen ${ }^{35}$ found Standardised Incidence Ratios (SIRs) of 1.8 for buccal cavity and pharynx cancers (10 observed) and 1.7 for larynx cancers (three observed) in women exposed to TCE in a Danish cohort study including more than 340 companies with documented use of TCE. Interestingly, the SIRs among men were lower, around 1.1 to 1.2 . Boice $e t a l^{6}$ reported not significantly elevated Standardised Mortality Ratio (SMR) for buccal cavity and pharynx cancers (four observed) and for larynx cancers (two observed) among men exposed to TCE in a rocket engine testing facility. In 2013, Hansen et $a P^{37}$ established a pooled cohort including 5553 workers with well-documented individual exposure to TCE in Finland, Sweden and Denmark. They observed an SIR for buccal and pharyngeal cancers of $1.71(95 \%$ CI 0.74 to 3.38$)$ and 2.94 (95\% CI 0.36 to 10.6$)$ respectively among men (eight observed) and among women (two observed). For laryngeal cancers, the SIR was 1.46 (95\% CI 0.72 to 2.61 ) in men (11 observed) and no case was observed in women. In a cohort of aircraft maintenance workers, ${ }^{38}$ a non-significantly increased risk of oral and pharyngeal cancer was observed for workers exposed versus not exposed to TCE among men (11 exposed cases, $\mathrm{OR}=1.23,95 \%$ CI 0.34 to 4.43$)$ and among women (two exposed cases, OR=1.08, 95\% CI 0.18 to 6.47 ), but no gradient with cumulative exposure was apparent. Overall, several studies of workers exposed to TCE have reported elevated but not statistically significant relative risks for oral, pharyngeal and/or laryngeal cancer, but the small number of cases and the lack of data on confounding factors make interpretation difficult. Our finding of a significantly increased risk of head and neck cancer associated with TCE exposure, based on a case-control study with larger numbers of exposed cases and with thorough adjustment for alcohol and tobacco consumption is globally consistent with the literature. We also observed a duration-response relationship. Concerning cumulative exposure, our results are less conclusive, with similar ORs below and above the median, but a globally significant trend with CEI. The increase in risk associated with TCE was larger for laryngeal cancer $(\mathrm{OR}=3.80,95 \%$ CI 1.55 to 9.32$)$, and somewhat smaller for cancer of the oral cavity $(\mathrm{OR}=2.12,95 \%$ CI 0.97 to 4.60$)$.

Since the 1950s, PCE, another widely used chlorinated solvent, was used extensively in dry cleaning, metal degreasing and for cleaning machinery and equipment. IARC classified PCE as "probably carcinogenic to humans'. ${ }^{25}$ Since the 1990 s, its use has been more limited, particularly for metal degreasing, but it continues to be used for dry degreasing of clothes, albeit under stricter conditions. The literature on the risks of head and neck cancers related to exposure to PCE is very limited. Mundt et $a l^{99}$ reviewed the risk of cancer linked to PCE exposure. They concluded that the possibility of an association between oral, pharyngeal and laryngeal cancer and PCE appeared unlikely. In a cohort of dry cleaners, a significantly elevated SMR was observed for laryngeal cancer among workers with the highest estimated level of exposure to dry cleaning solvents, primarily PCE. ${ }^{40}$ Deaths from cancer of the buccal cavity and pharynx were not in excess in this cohort. In another cohort of dry cleaners, exposure to PCE was found to be associated with a significant increase in tongue cancer, but not in laryngeal cancer. ${ }^{41}$ As for TCE, these findings rely on small numbers of cases, and information on confounding factors was not available. A case-control study showed a high, although not significant, OR associated with exposure to PCE, after adjustment for alcohol and tobacco consumption. ${ }^{42}$ In another case-control study, in which smoking and alcohol drinking were controlled for, a significantly increased risk of laryngeal cancer was also found to be associated with exposure to chlorinated solvents, but information on specific solvents was not available. ${ }^{24}$ In line with these results, we observed elevated ORs for laryngeal cancers in relation with PCE (four exposed cases, $\mathrm{OR}=7.95,95 \%$ CI 1.92 to 32.9 ).

In our study, it is not possible to distinguish precisely the risks associated with TCE from those associated with PCE. Indeed, no woman in our study was exposed only to PCE. However, the study of combinations of exposures to different chlorinated solvents suggests that the risk for 


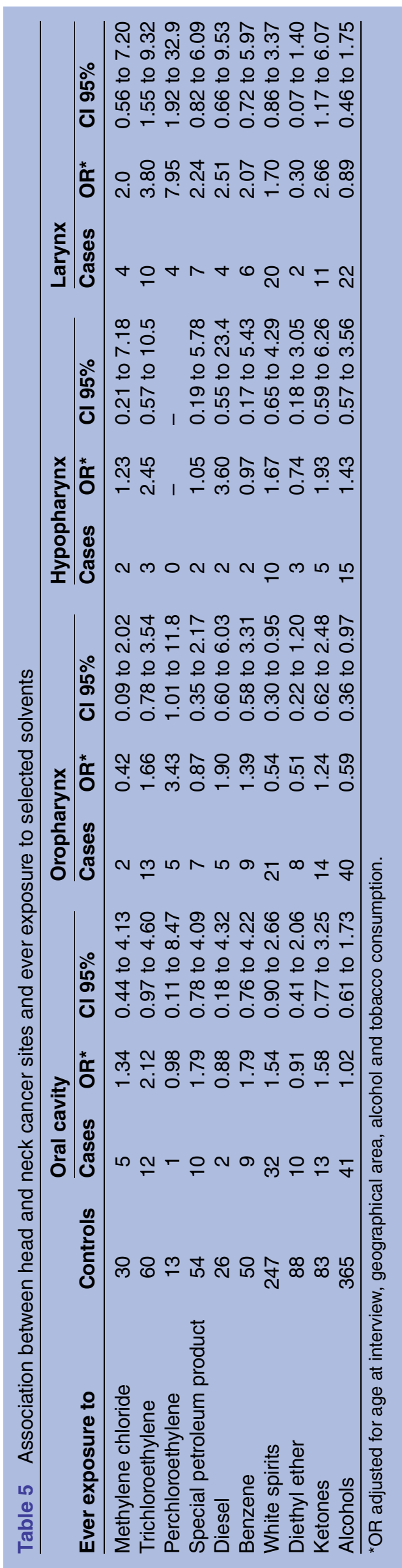

joint exposure to TCE and PCE (nine exposed cases, $\mathrm{OR}=4.47,95 \%$ CI 1.27 to 15.8 ) is higher than for exposure to TCE only (20 exposed cases, OR=1.81, 95\% CI 0.81 to 4.04$)$.

Overall, our results are consistent with an effect of occupational exposure to these two chlorinated solvents on the occurrence of head and neck cancers, particularly with laryngeal cancer. Among men in the ICARE study ${ }^{43}$ there was also an increased risk of laryngeal cancer associated with high levels of exposure to PCE. However, no association was found between head and neck cancer and exposure to TCE in men, after adjustment for asbestos exposure. This difference in results between men and women is probably due to confounding by asbestos. In women, jobs involving exposure to TCE, mainly related to leather work or dry cleaning, are unlikely to entail exposure to asbestos, and actually adjusting for asbestos had no or very limited effect on the risk related to TCE in women. In men, the stronger correlation between asbestos and TCE exposure made it difficult to study an independent role of TCE. Another possible explanation is that there are true gender differences in risk. Some studies, although based on very small numbers, have suggested higher relative risks in women than in men, and gender differences in the toxicokinetics of TCE have been reported. ${ }^{28} 2944$

Petroleum solvents, and even more so oxygenated solvents, are also widely used by women in the workplace. Overall, our results do not provide evidence of a substantial role of these solvents in head and neck cancer aetiology. However, we found a significantly increased risk of cancer of the oral cavity among women exposed for more than 10 years to white spirits, as well as a significantly increased risk of laryngeal cancer associated with exposure to ketones. To the best of our knowledge, these associations have not been examined previously. Although these findings may be due to chance, they warrant further investigation.

One strength of our study is that it included almost 300 female incident cases of well-characterised squamous cell carcinomas of the head and neck (HNSCC). This makes it one of the largest case-control studies in women. The design of ICARE was population-based; cases were incident and were identified by qualified cancer registries in 10 French geographical areas. It was verified that the distribution of the main occupational and economic activity characteristics of the active population in these regions was similar to their distribution in France. ${ }^{30}$ Participation rates were satisfactory for a population-based case-control study. ${ }^{30}$ The control group was a random sample of the population of these areas and the distribution of socioeconomic characteristics was also similar to their distribution in the general population. Moreover, lifelong exposure prevalences among women controls were of the same order of magnitude as those estimated among women in the general population for the solvents under study. ${ }^{33}$ Distribution by age, sex and cancer site of the head and neck cancer 
cases included in ICARE was similar to that observed for head and neck cancer cases in all of France. Thus, selection bias is unlikely, and was probably marginal if it occurred at all.

Our study has some limitations. Despite a relatively large number of cases, statistical power was limited for in-depth analyses by cancer sites. As this is a casecontrol study, recall bias is possible. However, it should be very limited since the number of jobs reported by cases and controls was similar (on average 3.3 for cases and 3.7 for controls). Although occupations and industries are self-reported, it is unlikely that this bias would be differential between cases and controls because occupational exposures are not widely known to be risk factors for head and neck cancers, particularly among women. Coding occupation and industry is difficult and often not reproducible. However, coders received special training and were blind as to case-control status. If coding errors were made, they were therefore not differential. Residual confounding is always a possibility. But we took into account age, alcohol and tobacco consumption, the interaction between alcohol and tobacco, and socioeconomic status. Special attention was paid to adjustment for alcohol and tobacco consumption, with the use of cubic splines allowing to better account for the effect of these two confounding factors. Therefore, residual confounding in relation with alcohol and tobacco consumption is unlikely to be a major problem in this study. However, other known or suspected risk factors such as nutritional factors or human papilloma virus infection were not considered in this analysis but it is unlikely that they explain the observed associations.

Another limitation of our study is that this type of JEM analysis, based on job-specific averages, does not achieve a high level of accuracy in the exposure assessment. ${ }^{45}$ The use of JEMs may produce misclassification of exposure, which is likely to be independent of case-control status. Non-differential misclassification bias results in an estimation of the OR biased towards 1, with an associated loss of statistical power for dichotomised exposures, ${ }^{46}$ but may also distort exposure-response trends in multilevel exposure analyses. ${ }^{47}$ In our categorical analyses for TCE and PCE, we found duration-response relationships, but no dose-response relation with intensity, and consequently no dose-response relation with cumulative exposure. Assessment of exposure levels is more prone to error than duration, so misclassification could partly explain our findings. Furthermore, the JEMs used are not gender specific. The construction of the JEMs ${ }^{33}$ was based primarily on knowledge acquired from men, and misclassification may be more frequent among women. However, this type of bias cannot explain positive findings.

Finally, we assessed a large number of associations, and multiple comparisons may be an issue. Instead of applying an overly conservative adjustment, we chose to rely on the consistency of results between the different exposure variables, as well as on published results, to draw our conclusions. ${ }^{48} 49$

\section{CONCLUSION}

In conclusion, our findings suggest that the exposure to TCE and PCE may increase the risk of HNSCC; in contrast, there is no clear evidence that the other solvents studied are risk factors for HNSCC. Nevertheless, further investigations are necessary to replicate these results in a larger, exposed female population.

Author affiliations

${ }^{1}$ Population-based Epidemiologic Cohorts Unit, Inserm, Villejuif, France

${ }^{2}$ University of Versailles St-Quentin, Villejuif, France

${ }^{3}$ Faculté de Médecine, Inserm U 1085-Institut de Recherche en Santé, Environnement et Travail (IRSET), Pointe-à-Pitre, France

${ }^{4}$ Sorbonne Universités, UPMC Univ Paris 06, INSERM, Institut Pierre Louis d'épidémiologie et de Santé Publique (IPLESP UMRS 1136), Paris, France

${ }^{5}$ Inserm, CESP Centre for Research in Epidemiology and Population Health, Environmental Epidemiology of Cancer Team, Villejuif, France

${ }^{6}$ University Paris-Sud, Villejuif, France

${ }^{7}$ Department of Occupational Health, French Institute for Public Health

Surveillance, Saint Maurice, France

${ }^{8}$ UMRESTTE (Epidemiological Research and Surveillance Unit in Transport, Occupation and Environment), University Claude Bernard, Lyon, France

${ }^{9}$ Hérault Cancer Registry, Montpellier, France

Collaborators Members of ICARE Study Group: Registre des cancers du Calvados, France (Anne-Valérie Guizard); Registre des cancers du Doubs, France (Arlette Danzon, Anne-Sophie Woronoff); Registre des cancers du Bas-Rhin, France (Michel Velten): Registre des cancers du Haut-Rhin, France (Antoine Buemi, Émilie Marrer); Registre des cancers de l'Hérault, France (Brigitte Trétarre); Registre des cancers de l'Isère, France (Marc Colonna, Patricia Delafosse); Registre des cancers de Loire-Atlantique-Vendée, France (Paolo Bercelli, Florence Molinié); Registre des cancers de la Manche, France (Simona Bara); Registre des cancers de la Somme, France (Bénédicte Lapotre-Ledoux, Nicole Raverdy); Inserm, Centre for research in Epidemiology and Population Health (CESP), U1018, Environmental Epidemiology of Cancer Team, Villejuif, France (Sylvie Cénée, Oumar Gaye, Florence Guida, Farida Lamkarkach, Loredana Radoï, MS, IS); Inserm Epidemiologic Cohorts UnitUMS 011 INSERM-UVSQ, Villejuif, France (MC, DC, Annie Schmaus). University Lyon 1, UMRESTTE, Lyon, France: Joëlle Févotte. French Institute for Public Health Surveillance, Department of Occupational Health, Saint Maurice, France: CP. Sorbonne Universités, UPMC Univ Paris 06, INSERM, Institut Pierre Louis d'épidémiologie et de Santé Publique (IPLESP UMRS 1136), Paris, France (GM). Inserm U 1085-IRSET, Pointe-à-Pitre, France (DL). Institution at which the work was performed. Inserm, Epidemiologic Cohorts Unit - UMS 011 INSERM-UVSQ, Villejuif, France.

Contributors $M C$ and $D L$ designed the current study, conducted the analyses and drafted the manuscript; $\mathrm{CB}$ and GM contributed to the statistical analysis and interpretation of the results. DC, CP and BT were involved in data collection, management and quality control. DL and IS are the principal investigators of the ICARE study, conceived this study and coordinated the original collection of the data. All the authors critically reviewed and revised the manuscript, and gave their approval for its final version.

Funding The ICARE study was funded by the French National Research Agency (ANR); French National Cancer Institute (INCA); French Agency for Food, Environmental and Occupational Health and Safety (ANSES); French Institute for Public Health Surveillance (InVS); Fondation pour la Recherche Médicale (FRM); Fondation de France; Association pour la Recherche sur le Cancer (ARC); Ministry of Labour (Direction Générale du Travail); Ministry of Health (Direction Générale de la Santé). The present work was supported by a grant from the 'Fondation ARC pour la recherche sur le cancer'.

\section{Competing interests None declared.}

\section{Patient consent Obtained.}

Ethics approval Institutional Review Board of the French National Institute of Health and Medical Research (IRB-Inserm, number 01-036) and the French Data Protection Authority (CNIL number 90 120). 
Provenance and peer review Not commissioned; externally peer reviewed.

Data sharing statement No additional data are available.

Open Access This is an Open Access article distributed in accordance with the Creative Commons Attribution Non Commercial (CC BY-NC 4.0) license, which permits others to distribute, remix, adapt, build upon this work noncommercially, and license their derivative works on different terms, provided the original work is properly cited and the use is non-commercial. See: http:// creativecommons.org/licenses/by-nc/4.0/

\section{REFERENCES}

1. Ferlay J, Parkin DM, Steliarova-Foucher E. Estimates of cancer incidence and mortality in Europe in 2008. Eur J Cancer 2010;46:765-81.

2. Binder-Foucard F, Bossard N, Delafosse $P$, et al. Cancer incidence and mortality in France over the 1980-2012 period: solid tumors. Rev Epidemiol Sante Publique 2014;62:95-108.

3. Secretan B, Straif K, Baan R, et al. A review of human carcinogens--Part E: tobacco, areca nut, alcohol, coal smoke, and salted fish. Lancet Oncol 2009;10:1033-4.

4. Hashibe M, Brennan P, Chuang SC, et al. Interaction between tobacco and alcohol use and the risk of head and neck cancer: pooled analysis in the International Head and Neck Cance Epidemiology Consortium. Cancer Epidemiol Biomarkers Prev 2009;18:541-50.

5. Boffetta P, Gridley G, Gustavsson P, et al. Employment as butcher and cancer risk in a record-linkage study from Sweden. Cancer Causes Control 2000;11:627-33.

6. Boffetta P, Richiardi L, Berrino F, et al. Occupation and larynx and hypopharynx cancer: an international case-control study in France, Italy, Spain, and Switzerland. Cancer Causes Control 2003;14:203-12.

7. Brown LM, Mason TJ, Pickle LW, et al. Occupational risk factors for laryngeal cancer on the Texas Gulf Coast. Cancer Res 1988:48:1960-4.

8. De Stefani E, Boffetta $\mathrm{P}$, Oreggia $\mathrm{F}$, et al. Occupation and the risk of laryngeal cancer in Uruguay. Am J Ind Med 1998:33:537-42.

9. Dietz A, Ramroth $\mathrm{H}$, Urban $\mathrm{T}$, et al. Exposure to cement dust, related occupational groups and laryngeal cancer risk: results of a population based case-control study. Int J Cancer 2004;108:907-11.

10. Goldberg P, Leclerc A, Luce D, et al. Laryngeal and hypopharyngeal cancer and occupation: results of a case control-study. Occup Environ Med 1997;54:477-82.

11. Merletti F, Boffetta P, Ferro G, et al. Occupation and cancer of the oral cavity or oropharynx in Turin, Italy. Scand J Work Environ Health 1991;17:248-54.

12. Muscat JE, Wynder EL. Tobacco, alcohol, asbestos, and occupational risk factors for laryngeal cancer. Cancer 1992;69:2244-51.

13. Paget-Bailly S, Guida F, Carton M, et al. Occupation and head and neck cancer risk in men: results from the ICARE Study, a French Population-Based Case-Control Study. J Occup Environ Med 2013;55:1065-73.

14. Richiardi L, Corbin M, Marron M, et al. Occupation and risk of upper aerodigestive tract cancer: the ARCAGE study. Int $J$ Cancer 2012;130 (2397-406

15. Schildt EB, Eriksson M, Hardell L, et al. Occupational exposures as risk factors for oral cancer evaluated in a Swedish case-control study. Oncol Rep 1999;6:317-20.

16. Wortley P, Vaughan TL, Davis S, et al. A case-control study of occupational risk factors for laryngeal cancer. $\mathrm{Br} J$ Ind Med 1992:49:837-44.

17. Zagraniski RT, Kelsey JL, Walter SD. Occupational risk factors for laryngeal carcinoma: Connecticut, 1975-1980. Am J Epidemiol 1986;124:67-76

18. Czene K, Tiikkaja S, Hemminki K. Cancer risks in hairdressers: assessment of carcinogenicity of hair dyes and gels. Int $\mathrm{J}$ Cancer 2003;105:108-12

19. Huebner WW, Schoenberg JB, Kelsey JL, et al. Oral and pharyngeal cancer and occupation: a case-control study. Epidemiology 1992;3:300-9.

20. Ji J, Hemminki K. Occupation and upper aerodigestive tract cancers: a follow-up study in Sweden. J Occup Environ Med 2005;47:785-95.

21. Pukkala E, Martinsen JI, Lynge $\mathrm{E}$, et al. Occupation and cancerfollow-up of 15 million people in five Nordic countries. Acta Oncol 2009;48:646-790

22. Carton M, Guida F, Paget-Bailly S, et al. Occupation and head and neck cancer in women-Results of the ICARE study. Am J Ind Med 2014;57:1386-97.
23. Berrino F, Richiardi L, Boffetta $P$, et al. Occupation and larynx and hypopharynx cancer: a job-exposure matrix approach in an international case-control study in France, Italy, Spain and Switzerland. Cancer Causes Control 2003;14:213-23.

24. Shangina O, Brennan P, Szeszenia-Dabrowska N, et al. Occupational exposure and laryngeal and hypopharyngeal cancer risk in central and Eastern Europe. Am J Epidemiol 2006;164:367-75.

25. IARC. Trichloroethylene, tetrachloroethylene, and some other chlorinated agents. IARC Monogr Eval Carcinog Risks Hum 2014:106:1-512.

26. Cogliano VJ, Baan R, Straif K. Updating IARC's carcinogenicity assessment of benzene. Am J Ind Med 2011:54:165-7.

27. Dananché B. Présentation de matrices emplois-expositions à cinq solvants chlorés. Quelques applications à un échantillon de population en France. Institut de veille sanitaire, 2009.

28. Fisher JW, Mahle D, Abbas R. A human physiologically based pharmacokinetic model for trichloroethylene and its metabolites, trichloroacetic acid and free trichloroethanol. Toxicol Appl Pharmacol 1998;152:339-59.

29. Sato A. Confounding factors in biological monitoring of exposure to organic solvents. Int Arch Occup Environ Health 1993;65 (uppl): S61-7.

30. Luce D, Stucker I, ICARE Study Group. Investigation of occupational and environmental causes of respiratory cancers (ICARE): a multicenter, population-based case-control study in France. BMC Public Health 2011:11:928.

31. International Labour Office. International standard classification of occupations. Geneva, Switzerland, 1968.

32. Institut National de la Statistique et des Etudes Economiques. Nomenclature des Activités Françaises, Révision 1. France, 2000.

33. Fevotte J, Dananche B, Delabre L, et al. Matgene: a program to develop job-exposure matrices in the general population in France. Ann Occup Hyg 2011;55:865-78.

34. Wartenberg D, Reyner D, Scott CS. Trichloroethylene and cancer: epidemiologic evidence. Environ Health Perspect 2000;108(Suppl 2):161-76.

35. Raaschou-Nielsen O, Hansen J, McLaughlin JK, et al. Cancer risk among workers at Danish companies using trichloroethylene: a cohort study. Am J Epidemiol 2003;158:1182-92.

36. Boice JD, Jr., Marano DE, Cohen SS, et al. Mortality among Rocketdyne workers who tested rocket engines, 1948-1999. J Occup Environ Med 2006;48:1070-92.

37. Hansen J, Sallmen M, Selden Al, et al. Risk of cancer among workers exposed to trichloroethylene: analysis of three Nordic cohor studies. J Natl Cancer Inst 2013;105:869-77.

38. Radican L, Blair A, Stewart P, et al. Mortality of aircraft maintenance workers exposed to trichloroethylene and other hydrocarbons and chemicals: extended follow-up. J Occup Environ Med 2008;50:1306-19.

39. Mundt KA, Birk T, Burch MT. Critical review of the epidemiological literature on occupational exposure to perchloroethylene and cancer. Int Arch Occup Environ Health 2003;76:473-91.

40. Blair A, Petralia SA, Stewart PA. Extended mortality follow-up of a cohort of dry cleaners. Ann Epidemiol 2003;13:50-6.

41. Calvert GM, Ruder AM, Petersen MR. Mortality and end-stage renal disease incidence among dry cleaning workers. Occup Environ Med 2011;68:709-16.

42. Vaughan TL, Stewart PA, Davis S, et al. Work in dry cleaning and the incidence of cancer of the oral cavity, larynx, and oesophagus. Occup Environ Med 1997;54:692-5.

43. Fayossé A, Menvielle G, Cyr D, et al. Head and neck cancer and occupational exposure to chlorinated solvents: results from the ICARE study. Occup Environ Med 2014;71:A99-A100.

44. Rusyn I, Chiu WA, Lash LH, et al. Trichloroethylene: mechanistic, epidemiologic and other supporting evidence of carcinogenic hazard. Pharmacol Ther 2014:141:55-68.

45. Stengel B, Pisani P, Limasset JC, et al. Retrospective evaluation of occupational exposure to organic solvents: questionnaire and job exposure matrix. Int J Epidemiol 1993;22(Suppl 2):S72-82.

46. Bouyer J, Dardenne J, Hemon D. Performance of odds ratios obtained with a job-exposure matrix and individual exposure assessment with special reference to misclassification errors. Scand J Work Environ Health 1995;21 (265-71.

47. Dosemeci M, Wacholder S, Lubin JH. Does nondifferential misclassification of exposure always bias a true effect toward the null value? Am J Epidemiol 1990;132:746-8

48. Goldberg M, Silbergeld E. On multiple comparisons and on the design and interpretation of epidemiological studies of many associations. Environ Res 2011;111:1007-9.

49. Rothman KJ. No adjustments are needed for multiple comparisons. Epidemiology 1990;1:43-6. 